\title{
CIRROSE EXPERIMENTAL INDUZIDA PELA INALAÇÃO DE TETRACLORETO DE CARBONO: adaptação da técnica e avaliação da peroxidação lipídica ${ }^{+}$
}

\author{
Ricardo Viégas CREMONESE ${ }^{1}$, Arthur Azambuja PEREIRA-FILHO ${ }^{1}$, Richard MAGALHÃES ${ }^{2}$, \\ Angelo Alves de MATTOS $^{3}$, Claudio Augusto MARRONI ${ }^{4}$, \\ Cláudio Galeano ZETTLER ${ }^{5}$ e Norma Possa MARRONI ${ }^{6}$
}

RESUMO - Racional - Administração a longo prazo de tetracloreto de carbono é modelo experimental para produzir fibrose hepática. O estresse oxidativo parece ser o mecanismo envolvido na hepatoxicidade por tetracloreto de carbono onde as espécies ativas de oxigênio têm importante papel na patogênese da fibrose hepática. Objetivos - Avaliar a eficácia de um modelo experimental de cirrose hepática induzida pela inalação de tetracloreto de carbono em ratos, bem como avaliar a peroxidação lipídica e as características do líquido de ascite neste modelo. Material e Métodos - Inicialmente, acompanhou-se a evolução dos achados histológicos, através da técnica de hematoxilina e eosina, mediante o uso de tetracloreto de carbono inalatório ao longo das diferentes semanas $\left(5^{a}, 7^{a}, 9^{a}, 12^{a}\right)$. Posteriormente, ao final da $15^{a}$ semana de estudo, os ratos, então divididos em três grupos (controle; controle + fenobarbital; e tetracloreto de carbono + fenobarbital), foram avaliados em sua histologia hepática, peroxidação lipídica e as características do líquido de ascite. Para as análises de peroxidação lipídica utilizaram-se as técnicas de substâncias reativas ao ácido tiobarbitúrico e de quimiluminescência. No líquido de ascite avaliaram-se a citologia e a bacteriologia. Resultados - Observou-se entre a $12^{a}$ e $15^{a}$ semanas de inalação o estabelecimento de cirrose em 100\% dos animais submetidos a inalação com tetracloreto de carbono, acompanhada de um aumento significante na peroxidação lipídica no fígado dos ratos inalados com tetracloreto de carbono. Evidenciou-se a presença de infecção do líquido de ascite em um dos sete casos nos quais esta estava presente. Conclusão - O método inalatório desenvolvido é eficaz na indução de cirrose hepática e formação de ascite, sendo o estresse oxidativo um dos principais mecanismos da indução de cirrose pelo tetracloreto de carbono.

DESCRITORES - Cirrose hepática experimental. Tetracloreto de carbono. Estresse oxidativo. Ascite.

Trabalho realizado no Laboratório de Fisiologia Digestiva, Departamento de Fisiologia, Instituto de Ciências Básicas da Saúde, Universidade Federal do Rio Grande do Sul - UFRGS, no Hospital Irmandade Santa Casa de Misericórdia de Porto Alegre (ISCMPA) e na Fundação Faculdade Federal de Ciências Médicas de Porto Alegre (FFFCMPA); Porto Alegre, RS.

Acadêmicos da Fundação Faculdade Federal de Ciências Médicas de Porto Alegre (FFFCMPA).

Residente de Gastroenterologia do Hospital de Clínicas de Porto Alegre.

Professor Doutor em Medicina. Professor Titular da Disciplina de Gastroenterologia da FFFCMPA. Coordenador do Curso de Pós-Graduação em Hepatologia da FFFCMPA/ ISCMPA.

Professor Doutor em Medicina. Professor Adjunto da Disciplina de Patologia da FFFCMPA.

Professor Mestre em Medicina. Professor Adjunto da Disciplina de Gastroenterologia da FFFCMPA. Hepatologista da Equipe de Transplante Hepático da ISCMPA. Professora Doutora responsável pelo Laboratório de Fisiologia Digestiva do Instituto de Ciências Básicas da Saúde da Universidade Federal do Rio Grande do Sul (ICBSUFRGS). Pesquisadora da Universidade Luterana do Brasil (ULBRA).

Endereço para correspondência: Dra. Norma Possa Marroni - Laboratório de Fisiologia Digestiva - ICBS-UFRGS - Av. Paulo Gama, 110 - $90040-060$ - Porto Alegre, RS. e-mail: nmarroni@zaz.com.br 


\section{INTRODUÇÃO}

O tetracloreto de carbono $\left(\mathrm{CCl}_{4}\right)$ é uma potente droga hepatotóxica que ocasiona dano hepático por intermédio de radicais livres formados durante a sua metabolização - o triclorometil $\left(\cdot \mathrm{CCl}_{3}\right)$ e o triclorometilperoxil $\left(\cdot \mathrm{OOCCl}_{3}\right)^{(25,31)}$. A indução do sistema de enzimas oxidativas, através da administração de fenobarbital, intensifica a necrose hepática produzida pelo $\mathrm{CCl}_{4}{ }^{(15,22)}$. O primeiro estudo avaliando a cirrose por $\mathrm{CCl}_{4}$ foi descrito por CAMERON e KARUNARATE, em $1936^{(3)}$.

$\mathrm{O}$ uso de $\mathrm{CCl}_{4}$ por via inalatória é um modelo experimental efetivo de cirrose, tendo como inconveniente o fato de provocar alta mortalidade nos animais de experimentação ${ }^{(15,18,22)}$. Este modelo permite, a longo prazo, a obtenção de modificações histológicas e hemodinâmicas características da cirrose hepática e da hipertensão portal verificadas em humanos e parece ser o mais apropriado para o estudo da formação do líquido de ascite.

Na cirrose têm sido descritas alterações nos mecanismos oxidantes/ antioxidantes, que se encontram em desequilíbrio e contribuem em grande parte para a necrose hepática ${ }^{(1,15,25)}$. Os produtos originários da peroxidação lipídica parecem estimular a expressão dos genes responsáveis pela síntese de colágeno, um dos principais componentes da fibrose $\mathrm{e}^{(14,18,19)}$.

A alteração oxidativa dos lipídios das membranas celulares, formadas em grande parte por ácidos graxos poli-insaturados, pode levar à perda de sua funcionalidade através de alterações nos mecanismos de homeostase celular ${ }^{(15,25)}$. A propagação em cadeia da peroxidação lipídica forma compostos reativos com o oxigênio, ampliando o seu dano. Esta agressão acaba por interferir em mecanismos celulares importantes, incluindo sistemas enzimáticos, expressão gênica e mecanismos de segundo mensageiro, entre outros ${ }^{(25)}$.

O presente estudo, utilizando modelo experimental modificado de cirrose hepática induzida pela inalação de $\mathrm{CCl}_{4}$, procura acompanhar cronologicamente as alterações histológicas do fígado, avaliar o estresse oxidativo através das medidas de peroxidação lipídica no fígado, bem como avaliar as características do líquido de ascite em ratos cirróticos.

\section{MATERIAL E MÉTODOS}

Foram utilizados ratos machos Wistar, com peso médio de $250 \mathrm{~g}$, no início do experimento, e de $350 \mathrm{~g}$ no final. Os animais foram acondicionados em caixas plásticas (cinco animais por caixa), com ciclo de claro/escuro (12 horas), em ambiente com temperatura e umidade controladas, com livre acesso à água e ração (Purina - Nutripal, Porto Alegre, RS, Brasil).

Com o objetivo de provocar indução enzimática e abreviar o tempo necessário para o desenvolvimento da cirrose, foi adicionado, na água de beber dos animais, fenobarbital na concentração de $0,3 \mathrm{~g} / \mathrm{L}, 7$ dias antes da primeira inalação e, posteriormente, durante todo o experimento.

$\mathrm{O}$ grupo $\mathrm{CCl}_{4}$ foi exposto ao agente agressor duas vezes por semana (segundas e sextas-feiras), no interior de uma câmara de inalação com 47 x 34 x $18 \mathrm{~cm}$. $\mathrm{O} \mathrm{CCl}_{4}$ era colocado em um recipiente de vidro (umidificador), ligado a um compressor de ar com vazão de $1 \mathrm{~L} / \mathrm{min}$.

Nas primeiras três sessões, o tempo de exposição ao gás foi de meio minuto, permanecendo os animais no interior da câmara por outro meio minuto, com o compressor desligado. Na quarta sessão, o tempo de gaseado aumentava para 1 minuto, seguido de outro minuto de permanência no interior da câmara. Posteriormente, a exposição ao gás e o subseqüente período de permanência na câmara aumentavam de meio minuto a cada três sessões, alcançando-se o tempo máximo de 5 minutos em 15 semanas.

Em diferentes tempos do estudo, após um jejum de 12 horas, os animais eram anestesiados com cloridrato de cetamina (Ketalar ${ }^{\circledR} 100$ $\mathrm{mg} / \mathrm{kg}$ ) e submetidos a retirada dos órgãos para a realização dos estudos.

Inicialmente, 20 animais foram submetidos a inalação de $\mathrm{CCl}_{4}$ com o objetivo de analisar a evolução do padrão histológico hepático em diferentes momentos de exposição ao agente agressor ( $5^{\mathrm{a}}, 7^{\mathrm{a}}, 9^{\mathrm{a}}, 12^{\mathrm{a}}$ semana $)$.

Em um segundo momento, 30 animais foram submetidos a um período de 15 semanas de observação para a posterior avaliação da peroxidação lipídica (PL), das características do líquido de ascite e da histologia ao final de 15 semanas. Os grupos constituíram-se de: 10 ratos controles (CO), 10 controles + fenobarbital (CO+FENO) e 10 ratos tetracloreto de carbono + fenobarbital $\left(\mathrm{CCl}_{4}\right)$, tendo ocorrido neste último grupo dois óbitos, o que levou à análise de oito ratos ao final do estudo.

\section{Avaliação Citológica e Bacteriológica do Líquido de Ascite}

Coletava-se, quando presente, o líquido de ascite em tubos com EDTA (Vacutainer) e em tubos com meio de cultura para posterior análise citológica e bacteriológica, respectivamente, ambas realizadas no Laboratório Central da Irmandade Santa Casa de Misericórdia de Porto Alegre, RS.

\section{Avaliação Histológica}

Os fragmentos de fígado, fixados com formalina, foram corados com hematoxilina-eosina e observados em microscopia óptica (40x). A avaliação histológica era realizada no Departamento de Patologia da Fundação Faculdade Federal de Ciências Médicas de Porto Alegre, RS, por patologista experiente em patologia hepática.

\section{Avaliação da Peroxidação Lipídica}

Preparo do homogeneizado: após a excisão completa do fígado e a retirada do material para fixação em formalina, era ressecada a região correspondente à porção medial do lobo direito $(1,5 \times 0,5 \times 0,5 \mathrm{~cm})$ 
Cremonese RV, Pereira-Filho AA, Magalhães R, Mattos AA de, Marroni CA, Zettler CG, Marroni NP. Cirrose experimental induzida pela inalação de tetracloreto de carbono: adaptação da técnica e avaliação da peroxidação lipídica

para a homogeneização. $\mathrm{O}$ fragmento do fígado antes da homogeneização, era mantido a uma temperatura de $2^{\circ} \mathrm{C}$ em solução fisiológica.

No tubo de homogeneização era colocado $9 \mathrm{~mL}$ de tampão fosfato ( $\mathrm{KCl} 140 \mathrm{mM}$, fosfato $20 \mathrm{mM}$ - $\mathrm{pH} 7,4$ ) por grama de tecido. O fígado era homogeneizado em Ultra-Turrax (IKA-WERK), à temperatura de $2{ }^{\circ} \mathrm{C}$ por 30 segundos. Este homogeneizado era centrifugado (SORVALL RC-5B Refrigerated Superspeed Centrifuge) por $10 \mathrm{~min}$ a $3000 \mathrm{rpm}^{(7)}$. O sobrenadante era pipetado em "eppendorfs" e o precipitado era desprezado. As amostras eram acondicionadas a temperatura de $-80^{\circ} \mathrm{C}$ para a posterior utilização nas medidas de PL.

Teste das substâncias reativas ao ácido tiobarbitúrico (TBA-RS): Na técnica era medida a quantidade de malondialdeído derivado da PL, aquecendo a $100^{\circ} \mathrm{C}$ durante 15 minutos o material biológico a ser testado na presença de ácido tiobarbitúrico, sob condições ácidas, medindo a formação de um produto de cor, espectrofotometricamente $^{(2)}$. O sobrenadante era colocado em uma cubeta do espectrofotômetro (CARY 3E - UV- Visible Spectrophotometer VARIAN) para a leitura em $535 \mathrm{~nm}$. A concentração de TBA-RS nos homogeneizados foi expressa em nmol por $\mathrm{mg}$ de proteína, utilizando um coeficiente de extinção igual à $156 \mathrm{mM}^{-1} \mathrm{~cm}^{-1}$.

Determinação da quimiluminescência (QL) iniciada pelo hidroperóxido de tert-butil: era adicionado um hidroperóxido orgânico de origem sintética (hidroperóxido de tert-butil-3mM) ao homogeneizado do tecido em estudo, avaliando-se a capacidade de resposta através da determinação da QL produzida pela amostra. Em tecidos submetidos a estresse oxidativo, o valor da QL iniciada pelo hidroperóxido de tert-butil (t-BOOH), é maior que o valor correspondente a este tecido em condições fisiológicas (pré-estresse) ${ }^{(8)}$.

A QL foi medida em um contador com o circuito de coincidência desconectado e utilizando o canal de tritio (Liquid Scintillation Corenter, 1209 RACKBETA, LKB WALLAR). Os resultados foram expressos em contas por segundo (cps) por mg de proteína de energia luminosa, emitida pelo retorno ao estado fundamental de carbonilas excitadas e oxigênio "singlet" durante a PL. Para cálculo de QL iniciada pelo t-BOOH, foi considerada a emissão máxima descontada a emissão basal (a QL do vial com o tampão associado ao homogeneizado) ${ }^{(8)}$.

Dosagem de proteínas: a concentração de proteínas do fígado foi determinada para o ajuste nos cálculos dos testes de TBA-RS e QL. Neste método foi utilizada como padrão uma solução de albumina bovina (SIGMA) na concentração de $1 \mathrm{mg} / \mathrm{mL}$. Após os procedimentos, eram medidos os valores das amostras no espectrofotômetro a $625 \mathrm{~nm}^{(20)}$.

Este estudo foi aprovado pela Comissão de Pesquisa e Ética em Saúde do Grupo de Pesquisa e Pós-Graduação do Hospital de Clínicas de Porto Alegre.

Os resultados foram expressos em média + erro padrão (EP). A comparação entre os grupos foi realizada através do teste ANOVA, seguido pelo teste "t" de Student com os valores de $P<0,05$, tidos como significante.

\section{RESULTADOS}

\section{Histologia}

O aspecto histológico hepático dos animais do grupo controle (CO) ao final da $15^{\mathrm{a}}$ semana, pode ser observado na Figura 1. Tratase do padrão histológico normal do parênquima hepático.

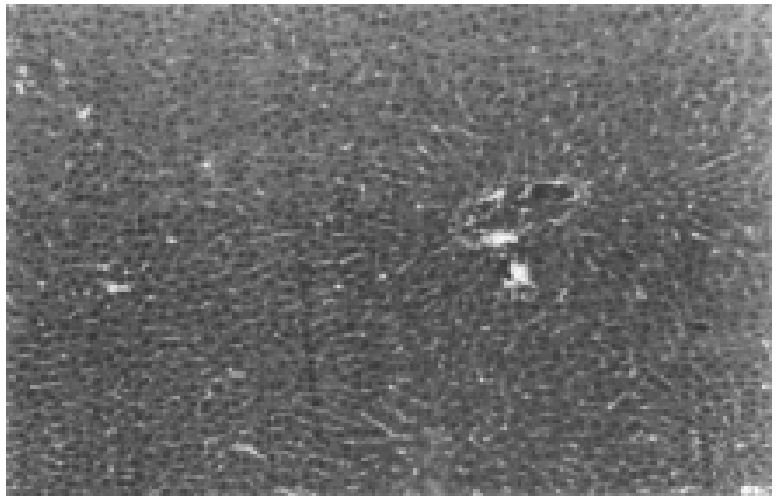

FIGURA 1 - Aspecto histológico do fígado de rato controle (CO). (hematoxilina-eosina - 40x)

Os achados histológicos dos fígados dos animais do grupo $\mathrm{CCl}_{4}$ foram avaliados em diferentes momentos de exposição à droga em quatro animais por semana determinada para o sacrifício. Os padrões histológico encontrados na $5^{\mathrm{a}}, 7^{\mathrm{a}}, 12^{\mathrm{a}}, 15^{\mathrm{a}}$ semanas estão apresentados nas Figuras 2, 3, 4, 5, respectivamente.

Os fígados dos animais do grupo CO+FENO foram avaliados histologicamente ao final do experimento e apresentaram características superponíveis aos dos animais do grupo controle (Figura 6).

Quinta semana (tempo de inalação de 1,5 minutos): presença de necrose hepatocelular e esteatose, comprometendo aproximadamente $50 \%$ do parênquima hepático, com discreta reação inflamatória (Figura 2).

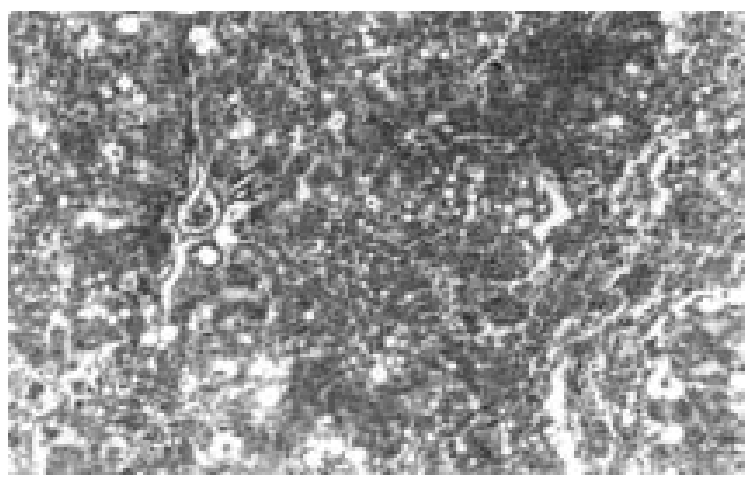

FIGURA 2 - Histologia hepática correspondente à quinta semana de inalação de $\mathrm{CCl}_{4}$. Presença de necrose e início da esteatose e processo inflamatório. (hematoxilina-eosina -100x) 
Sétima semana (tempo de inalação de 2,5 minutos): necrose hepatocelular e esteatose comprometendo mais de $70 \%$ do parênquima, com discreta reação inflamatória e fibrose septal (Figura 3).

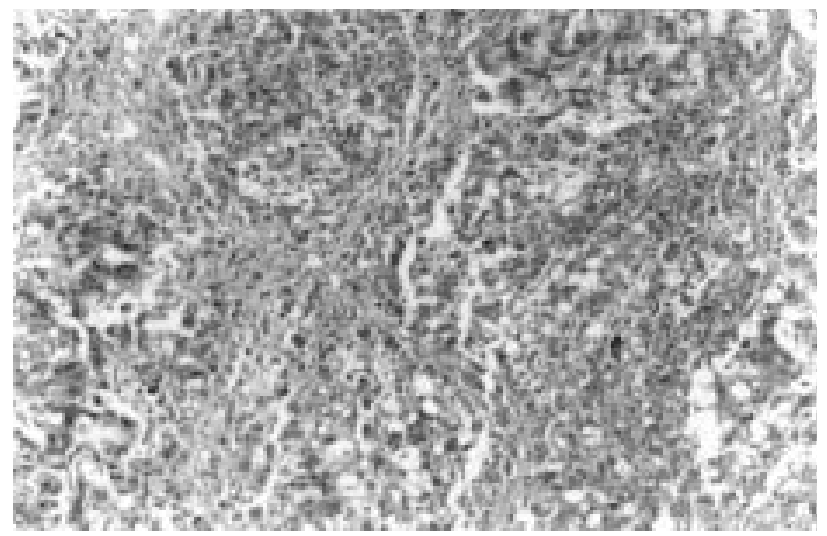

FIGURA 3 - Histologia hepática correspondente à sétima semana de inalação de $\mathrm{CCl}_{4}$. Presença de necrose e início de fibrose septal. (hematoxilina-eosina $-100 x$ )

Nona semana (tempo de inalação de 3 minutos): ausência de necrose hepatocelular e esteatose discreta. Fibrose intensa com formação de septos irregulares, tendendo à organização de nódulos e delimitando pequenos grupos hepatocitários.

Décima segunda semana (tempo de inalação de 4 minutos): achados semelhantes aos da nona semana, porém, mais intensos e associados à hiperplasia hepatocitária focal subcapsular (Figura 4).

Décima quinta semana (tempo de inalação de 5 minutos): cirrose micronodular estabelecida com septos espessos de fibrose (Figura 5).

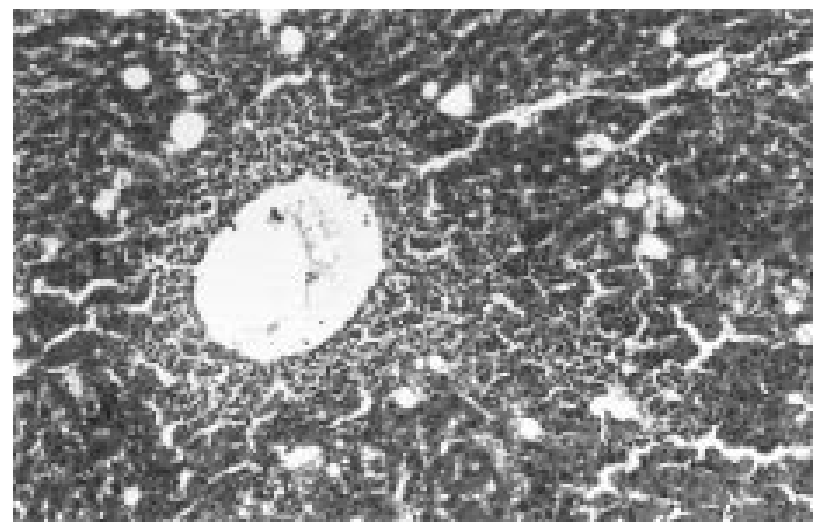

FIGURA 4 - Histologia hepática correspondente à $12^{\mathrm{a}}$ semana de inalação de $\mathrm{CCl}_{4}$. Fibrose intensa com proliferação subcapsular. (hematoxilina-eosina - 100x)

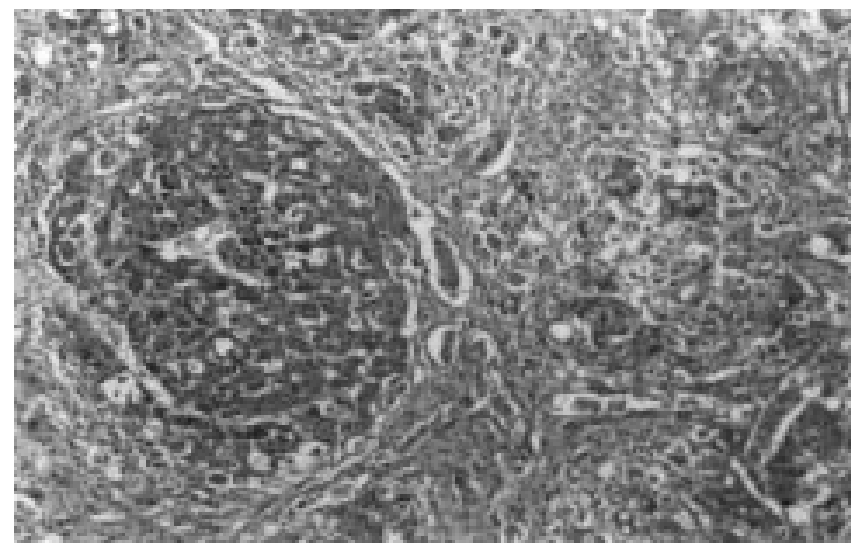

FIGURA 5 - Histologia hepática correspondente à $15^{\mathrm{a}}$ semana de inalação de $\mathrm{CCl}_{4}$. Aspecto nodular característico de cirrose hepática. (hematoxilina-eosina - 100x)

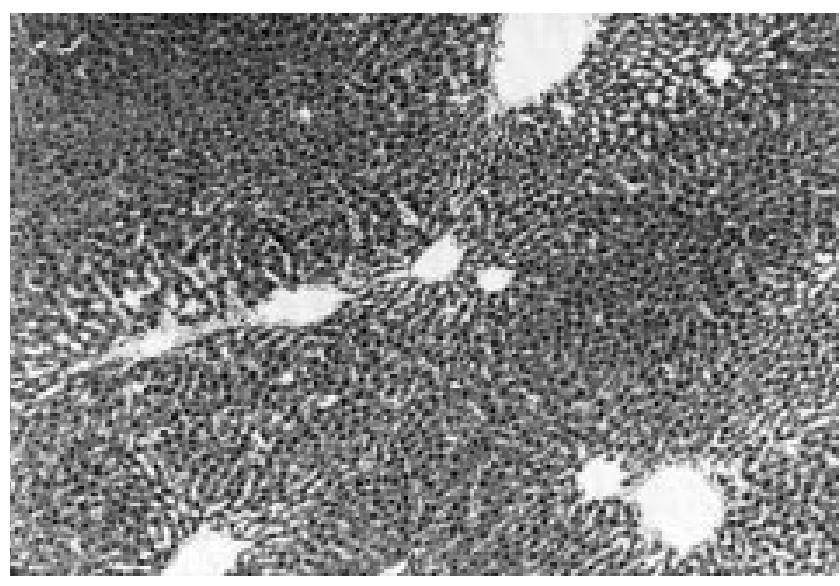

FIGURA 6 - Aspecto histológico do fígado de rato CO + FENO (hematoxilina-eosina - 40x).

\section{Avaliação do Líquido de Ascite}

A paracentese foi realizada nos animais ao final da $15^{\mathrm{a}}$ semana de inalação, imediatamente antes do sacrifício eletivo dos mesmos. $\mathrm{O}$ material era imediatamente transferido para frascos a vácuo para a análise citológica e bacteriológica (frascos de hemocultura).

Dos oito animais com 15 semanas (5 minutos de inalação) submetidos a paracentese prévia ao sacrifício, sete apresentaram líquido de ascite com um volume que variou de $4 \mathrm{~mL}$ em um animal até $20 \mathrm{~mL}$ para outros.

No exame citológico, a contagem de leucócitos apresentou média de 655 leucócitos $/ \mathrm{mm}^{3}$ com variação de 240 à 1250 leucócitos $/ \mathrm{mm}^{3}$.

$\mathrm{Na}$ avaliação bacteriológica observou-se ausência de germes com exceção de uma amostra que indicou presença de Proteus mirabilis e 
Enterococo $s p$. Neste caso, o número de leucócitos foi de 1250 leucócitos $/ \mathrm{mm}^{3}$.

\section{Peroxidação Lipídica - Técnicas de TBA-RS e QL}

Os resultados obtidos na avaliação da PL pelas técnicas de TBARS e QL podem ser observados na Tabela 1 e nos Gráficos 1 e 2.

$\mathrm{O}$ grupo $\mathrm{CCl}_{4}$ apresentou em ambas as técnicas de avaliação da PL, aumento significante do estresse oxidativo. Na técnica de TBARS o valor encontrado para o grupo CO foi de $0,284+0,03 \mathrm{nmol} / \mathrm{mg}$ de proteínas frente aos $0,630+0,04$ encontrados no grupo $\mathrm{CCl}_{4}$ $(P<0,05)$. Para a $Q \mathrm{~L}$, foram encontrados valores de 4.077,5+245,68 e de 7.798,05+526,77 cps/mg de proteína para os grupos $\mathrm{CO}$ e $\mathrm{CCl}_{4}$ $(P<0,05)$, respectivamente.

Os valores de peroxidação lipídica obtidos para o grupo $\mathrm{CCl}_{4}$, diferiram igualmente do grupo CO+FENO para um $P<0,05$ na técnica de QL. Não foi evidenciada alteração na PL perante o uso isolado de fenobarbital (CO+FENO), quando comparada com os resultados do grupo $\mathrm{CO}$.

\section{Mortalidade}

Quando se avaliou a sobrevida dos ratos, observou-se que, em 15 semanas, esta foi de $100 \%$ nos controles e de $80 \%$ naqueles tratados com $\mathrm{CCl}_{4}$.

Os óbitos ocorreram após a segunda sessão de 5 minutos, provavelmente em função de uma hepatite aguda sobreposta à doença hepática avançada. Estes animais não foram avaliados do ponto de vista da PL, do líquido de ascite ou da histologia devido ao tempo indeterminado entre o óbito e a identificação do mesmo, que pode chegar à $24 \mathrm{~h}$, comprometendo as interpretações sobre a possível etiologia das mortes.

Outro fato importante, visto em geral em modelos experimentais com ratos, é a grande freqüência com que estes se alimentam do animal morto nas caixas, alterando ainda mais qualquer parâmetro a ser avaliado.

\section{DISCUSSÃO}

Procurou-se, inicialmente, obter um modelo experimental de cirrose por inalação de tetracloreto de carbono, a partir do modelo modificado

TABELA 1 - Peroxidação lipídica no fígado dos ratos conforme as técnicas de TBA-RS e QL

\begin{tabular}{lcc}
\hline GRUPOS & TBA-RS (nmol/mg de proteína) & QL (cps/mg de proteína) \\
\hline CO (10) & $0,284+0,03$ & $4.077,5+245,68$ \\
CO+FENO (10) & $0,402+0,02$ & $4.128,01+261,30$ \\
CCl $_{\mathbf{4}}(\mathbf{8})$ & $0,630+0,04 *$ & $7.798,05+526,77 * /=$ \\
\hline$* P 0,05$ vs. grupo CO; & & \\
$=P<0,05$ vs. grupo CO+FENO; & & \\
$\left(\right.$ ) $\mathrm{n}^{\mathbf{0}}$ de animais/grupo.
\end{tabular}

TBA-RS

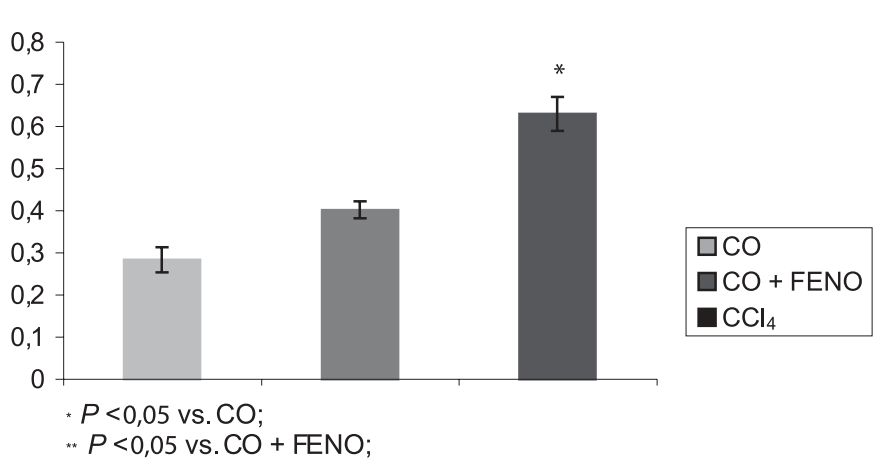

GRÁFICO 1 - Peroxidação lipídica conforme a técnica de TBA-RS.

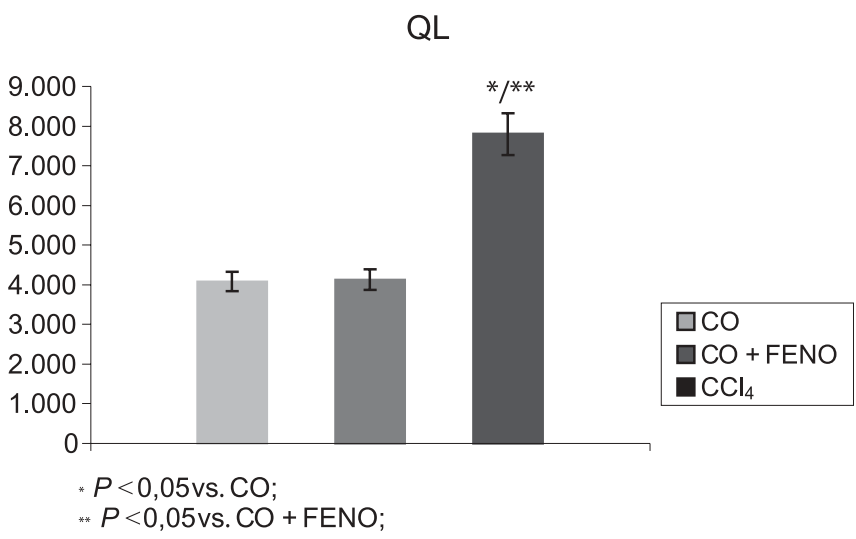

GRÁFICO 2 - Peroxidação lipídica conforme a técnica de QL. 
por LOPEZ-NOVOA et al. ${ }^{(18)}$, adaptando-o aos ratos Wistar, raça mais freqüentemente utilizada em nosso meio, a fim de se obter menor mortalidade, sem modificar as características de instalação da cirrose.

Os limites entre a agressão necessária para a produção da cirrose e a manutenção da sobrevida dos animais é muito tênue. Esta relação depende da dose do fármaco utilizado, da duração das sessões e do intervalo entre as mesmas ${ }^{(15)}$.

A administração aguda da droga causa necrose e esteatose centrolobular. Na administração crônica, a repetida exposição à droga promove a degeneração dos hepatócitos, ativando os mecanismos que culminam em fibrose e, posteriormente, em cirrose ${ }^{(15,26)}$.

A adaptação do método empregado caracterizou-se, essencialmente, por aumento mais gradual no tempo de gaseado de 30 segundos a cada três sessões, produzindo progressivo desarranjo do parênquima hepático, sem acarretar em mortalidade tão acentuada como ocorria inicialmente quando se utilizava incrementos de 1 minuto no tempo de inalação, segundo o proposto por CLÀRIA e JIMÉNEZ ${ }^{(6)}$ que, utilizando-o, mostraram mortalidade de $25 \%$ e $40 \%$ antes $\left(8-10^{\text {a }}\right.$ semanas) e depois (12-16 a semanas) da instalação da ascite, respectivamente ${ }^{(6,15)}$.

Através da modificação realizada, obteve-se mortalidade de $20 \%$, que parece adequada para o modelo proposto, haja vista a fragilidade da espécie Wistar frente aos ratos Sprague-Dawley. Desta forma, foi possível a avaliação histológica, a mensuração da agressão produzida pelos radicais livres oriundos da metabolização do $\mathrm{CCl}_{4}$ e o estudo das características do líquido de ascite, garantindo-se a efetividade do modelo.

Observou-se, a partir da quinta semana, necrose associada à esteatose hepatocelular, havendo progressivamente piora histológica por aumento da fibrose, atingindo-se o estágio de cirrose hepática micronodular na $15^{\text {a }}$ semana de inalação. Assim, os resultados obtidos, quando da administração crônica do $\mathrm{CCl}_{4}$, referendam as idéias propostas por JIMENEZ et al. ${ }^{(15)}$, no que diz respeito ao modelo experimental de cirrose.

No presente estudo, foi constatada a presença de ascite em mais de $80 \%$ dos ratos cirróticos, ocorrendo, todavia, crescimento bacteriano no líquido de ascite em apenas um animal. Como não foi observada fonte de infecção intra-abdominal, presume-se ser este um caso de peritonite bacteriana espontânea (PBE).

$\mathrm{O}$ fato de se ter observado crescimento de duas espécies de bactérias no líquido de ascite — situação incomum na $\mathrm{PBE}^{(21)}$ — vai ao encontro do trabalho de RUNYON et al. ${ }^{(30)}$, que observaram o crescimento de mais de uma bactéria em 33,3\% dos casos. Esses autores justificaram o fato baseando-se nas diferenças interespécies, já que a flora bacteriana do rato, bem como a porosidade de seu intestino eram diferentes, favorecendo maior translocação bacteriana.

Neste mesmo estudo, entretanto, constatou-se o desenvolvimento de infecção no líquido de ascite em 55,3\% dos ratos avaliados ${ }^{(30)}$. A baixa prevalência de infecção constatada no presente estudo, encontra explicação no modelo utilizado, uma vez que nos casos avaliados por RUNYON et al. ${ }^{(30)}$, os animais não eram sacrificados e era esperada a evolução natural da doença, até a morte, permitindo maior possibilidade de desenvolvimento da infecção do líquido de ascite. Não pode ser afastada, no trabalho desses autores, a possibilidade de contaminação "post mortem" ou eventual dano da mucosa do tubo digestivo, em decorrência da administração oral de $\mathrm{CCl}_{4}$, o que poderia favorecer à infecção. No presente estudo, ao utilizar-se o modelo inalatório de indução de cirrose, evitou-se este viés.

CASAFORT et al. ${ }^{(4)}$, em estudo de ratos cirróticos induzidos por $\mathrm{CCl}_{4}$ via oral, constataram a presença de peritonite bacteriana espontânea em $48 \%$ dos ratos com ascite. A elevada prevalência observada, também encontra explicação no tipo de modelo experimental proposto, uma vez que $80 \%$ dos casos se estabeleceram em animais com má-nutrição induzida por restrição alimentar ${ }^{(30,31)}$.

Os resultados obtidos na avaliação da peroxidação lipídica (Tabela 1 e Gráficos 1 e 2), evidenciam aumento do estresse oxidativo nos animais que utilizaram $\mathrm{CCl}_{4}$. Este achado sugere uma relação entre as alterações no parênquima hepático provocados pelo $\mathrm{CCl}_{4}$ e a formação das espécies ativas de oxigênio pelo sistema microssomal hepático, possivelmente através da formação dos radicais triclorometil $\left(\cdot \mathrm{CCl}_{3}\right)$ e triclorometilperoxil $\left(\bullet \mathrm{OOCCl}_{3}\right)$. Este último, reagindo rapidamente com o $\mathrm{O}_{2}$, origina um radical extremamente lesivo ${ }^{(15)}$.

O estudo da relação entre a fibrose hepática e a PL tem tido, recentemente, grande espaço na literatura. PERES et al. ${ }^{(25)}$ avaliaram a PL em modelos de cirrose produzida pela obstrução do ducto biliar, onde encontraram intensa fibrose nos ratos cirróticos. Acredita-se, atualmente, que as principais células responsáveis pela produção do colágeno na cirrose sejam os miofibroblastos após sofrerem transformação fenotípica diante de processos lesivos ao parênquima hepático ${ }^{(10,14,17)}$.

Algumas citocinas já foram relacionadas ao controle da expressão dos miofibroblastos. Assim, agem inibindo-o, tais como o interferongama, interferon-alfa, fator de crescimento hepatocitário e interleucina10 , ou ativando-o, como ocorre com o fator de crescimento tumoralbeta (TGF-beta) e com o fator de necrose tumoral-alfa (TNF-alfa) ${ }^{(9}$, $11,13,14,19)$.

O grau de fibrose e o nível de estresse oxidativo têm sido relacionados na literatura através de várias técnicas de mensuração de peroxidação lipídica. Entretanto, deve-se salientar que a partir de determinado grau de lesão do parênquima hepático, pode-se obter resultados conflitantes, devido a diminuição de tecido íntegro suscetível à ação dos radicais livres.

Referendando o papel do estresse oxidativo, RHODEN et al. ${ }^{(28)}$ sugerem que a indução da cirrose por $\mathrm{CCl}_{4}$ intraperitonial possa resultar de processos de isquemia e reperfusão tecidual e/ou a diminuição das defesas antioxidantes existentes. HALIM et al. ${ }^{(12)}$ demonstraram, em 
ratos, que o uso de antioxidantes, tais como silimarina $(30 \mathrm{mg} / \mathrm{kg})$, vitamina E $200 \mathrm{IU} / \mathrm{kg}$ e vitamina C $(50 \mathrm{mg} / \mathrm{kg})$ modulavam significativamente os distúrbios causados por $\mathrm{CCl}_{4}$, podendo eventualmente ser importantes na profilaxia da lipoperoxidação e conseqüente fibrose hepática causada pelos radicais livres ${ }^{(7,12)}$.

Acreditando no papel crucial do estresse oxidativo na fisiopatologia da fibrogênese hepática, vários autores ${ }^{(5,24,27,28,29)}$ intentam resguardar a função hepática através do uso de colchicina, colchicina e silimarina associadas, do ácido ursodeoxicólico, do beta-caroteno e do ácido trimetilcolchicina, apresentando resultados controversos. A colchicina, por exemplo, foi capaz de reduzir significativamente a peroxidação lipídica em ratos cirróticos por $\mathrm{CCl}_{4}$ intraperitonial, porém sem produzir efetiva proteção contra a fibrogênese $\mathrm{e}^{(16,23)}$.

A avaliação das enzimas catalase, superóxido dismutase e glutationa poderiam ser de grande utilidade para a avaliação do comportamento das defesas antioxidantes do organismo, diante de situação capaz de provocar cirrose hepática ${ }^{(17,32)}$.

Estudos recentes têm demonstrado que o uso de flavonóides, tipo rutina e quercitina, na cirrose biliar secundária por ligadura do ducto biliar em ratos, reduz marcadamente a lesão hepática, melhorando as provas de função hepática (AST, ALT e fosfatase alcalina) e diminuindo a lipoperoxidação, inibindo a proliferação de ducto biliar e atenuando a fibrose hepática ${ }^{(25)}$.

Conclui-se que a cirrose hepática induzida pela inalação de $\mathrm{CCl}_{4}$, conforme a modificação proposta, é um método experimental eficaz, no qual a lesão hepática provavelmente se origina a partir da formação de radicais livres, correspondente aos achados de PL no presente estudo. Acredita-se que a via inalatória de administração do $\mathrm{CCl}_{4}$ deva ser preferida em estudos que busquem avaliar a formação e tratamento da ascite, bem como da peritonite bacteriana espontânea.

O modelo apresentado poderá ser utilizado posteriormente na análise da interação entre oxidantes/antioxidantes na busca de drogas hepatoprotetoras capazes de prevenir ou, ao menos, amenizar o surgimento da cirrose.

\section{AGRADECIMENTOS}

Os autores agradecem aos acadêmicos de Medicina Bolsistas de Iniciação Científica que muito colaboraram com esse trabalho: Clarissa Ortiz, Juliano Magalhães e Carlos Caye.

Cremonese RV, Pereira-Filho AA, Magalhães R, Mattos AA de, Marroni CA, Zettler CG, Marroni NP. Experimental cirrhosis induced by carbon tetrachloride inhalation: technical modifications and lipoperoxidation effects. Arq Gastroenterol 2001;38(1):40-47.

ABSTRACT - Background - Long-term administration of carbon tetrachloride is an accepted experimental model to produce hepatic fibrosis. Oxidative stress has been postulated as a major molecular mechanism involved in carbon tetrachloride hepatotoxicity, where the reactive oxigen species play an important role in the pathogenesis of liver fibrosis. Aims - This study was conducted to evaluate the effectiveness of an experimental model of hepatic cirrhosis induced by carbon tetrachloride inhalation as well as the importance of lipid peroxidation and the characteristics of the ascitic fluid in this model. Methods - At first the hepatic histologic findings were assessed using the hematoxilineosin technique in different moments of carbon tetrachloride inhalation $\left(5^{\text {th }}, 7^{\text {th }}, 9^{\text {th }}, 12^{\text {nd }}\right.$ weeks $)$. Later, at the end of 15 weeks of the study the rats were divided in three groups (control; control + phenobarbital; and carbon tetrachloride + phenobarbital) for lipid peroxidation, ascitic fluid and hystologic characteristics evaluation. For the lipid peroxidation analysis, thiobarbituric acid and QL techniques were used. Citologic and bacteriologic parameters were analysed in the ascitic fluid. Results - Cirrhosis was established in 100\% of carbon tetrachloride rats between the $12^{\text {nd }}$ and $15^{\text {th }}$ weeks with an elevation in the lipid peroxidation carbon tetrachloride rats' livers. Ascitic fluid infection was observed in one of seven rats who has developed ascitis. Conclusions - The carbon tetrachloride inhalation method developed in this study is effective in cirrhosis induction and ascitis formation, and the carbon tetrachloride cirrhosis physiopathogenesis is probably related to the oxidative stress instalation.

HEADINGS- Liver cirrhosis, experimental. Carbon tetrachloride. Oxidative stress. Ascites.

\section{REFERÊNCIAS BIBLIOGRÁFICAS}

1. Aleynik SI, Leo MA, Ma X, Aleynik MK, Lieber CS. Polyenylphosphatidylcholine prevents carbon tetrachloride-induced lipid peroxidation while it attenuates liver fibrosis. J Hepatol 1997;27(3):554-61.

2. Buege JA, Aust SD. Microsomal lipid peroxidation. Methods Enzymol 1978;52:302-10.

3. Cameron JR, Karunarate WAE. Carbon tetrachloride cirrhosis in relation to liver regeneration. J Pathol Bacteriol 1936;92:1-4.
4. Casafort F, Sanchez E, Martin L, Aguero J, Romero FP. Influence of malnutrition on the prevalence of bacterial translocation and spontaneous bacterial peritonitis in experimental cirrhosis in rats. Hepatology 1997;25:1334-7.

5. Cedillo A, Mourelle M, Muril P. Effect of colchicine and trimethilcolchicinic acid on $\mathrm{CCl}_{4}$ induced cirrhosis in the rat. Pharmacol Toxicol 1996;79:241-6.

6. Clària J, Jiménez W. Cirrosis hepática experimental y fisiopatología de la formación de ascitis en la enfermedad hepática crónica. Gastroenterol Hepatol 1992;15:171-82.

7. Favari L, Perez-Alvarez V. Comparative effects of colchicine and silymarin on $\mathrm{CCl}_{4}$ - chronic liver damage in rats. Arch Med Res 1997;28:11-7. 
8. Flecha BG, Llesuy S, Boveris A. A hydroperoxide-initiated chemiluminescence: an assay for oxidative stress in biopsies of heart, liver, and muscle. Free Radic Biol Med 1991;10:93-100.

9. Fort J, Pillete C, Veal N, Oberti F, Gallois Y, Douay O, Rosenbaum J, Cales P. Effects of long-term administration of interferon alpha in two models of liver fibrosis in rats. J Hepatol 1998;29:263-70.

10. Geraghty J, Angerson WJ, Carter DC. A study of regional gastric mucosal blood flow in a rat model of hepatic cirrhosis. Am J Physiol 1992;262(4 Pt1):G727-31.

11. Grossman HJ, White D, Grossman VL, Bhathal PS. Effect of interferon gamma on intrahepatic haemodynamics of the cirrhotic rat liver. J Gastroenterol Hepatol 1998; $13: 1058-60$

12. Halim AB, El-Ahmdy O, Hassab-Allah, Abdel-Galil F, Hafez Y, Darwish A. Biochemical effect of antioxidants on lipids and liver function in experimental induced liver damage. Ann Clin Biochem 1997;34(Pt 6):656-63.

13. Halliwel B, Gutteridge JMC. Free radicals in biology and medicine. 2.ed. Oxford: Oxford University Press; 1995. 543 p.

14. Hellerbrand C, Stefanovic B, Giordano F, Buchardt ER, Brenner DA. The role of TGF beta-1 in initiating hepatic stellate cell activation in vivo. J Hepatol 1999;30:77-87.

15. Jimenez W, Clària J, Arroyo V, Rodés J. Carbon tetrachloride induced cirrhosis in rats: an useful tool for investigating the patogenesis in chronic liver disease. $\mathrm{J}$ Gastroenterol Hepatol 1992; 7:90-7.

16. Knook DL, Bosma A, Seifert WF. Role of vitamin A in liver fibrosis. J Gastroenterol Hepatol 1995;10 Suppl 1:S47-9.

17. Lieber CS. Prevention and treatment of liver fibrosis based on pathogenesis. Alcohol Clin Exp Res 1999;23:944-9.

18. Lopez-Novoa JM, Navarro V, Rodicio JL, Hernando L. Cirrhosis experimental de instauración rápida. Cronologia de aparición de las lesiones hepáticas. Patologia 1976;9:233-40.

19. Louis H, Van Laethem JL, Wu W, Quertinmont E, Degraef C, Van Den Berg K, Demols A, Goldman M, Le Moine O, Geerts A, Deviere J. Interleukin-10 controls neutrophilic infiltration, hepatic proliferation, and liver fibrosis induced by carbon tetrachloride in mice. Hepatology 1998;28(6):1607-15.

20. Lowry OH, Rosebrough MJ, Farr AL, Randall RJ. Protein measurement with the foline reagent. J Biol Chem 1951;193:265-75.

21. Mattos AA. Peritonite bacteriana espontânea e suas variantes; epidemiologia, diagnóstico e história natural. GED Gastroenterol Endosc Dig 1994;13:97108 .
22. Mclean EK, Mclean AEM, Sutton PM. An improved method for producing cirrhosis of the liver in rats by simultaneous administration of carbon tetrachloride and phenobarbitone. Br J Exp Path 1969;5:502-6.

23. Mihas AA, Markov AK, Submony C. Protective effects of misoprostol on carbon tetrachloride-induced liver damage in the rat. Pharmacology 1991;42:283-6.

24. Nava-Ocampo AA; Suster S, Muriel P. Effect of colchicine and ursodeoxycholic acid on hepatocyte and erythrocyte membranes and liver histology in experimentally induced carbon tetrachloride cirrhosis in rats. Eur J Clin Invest 1997;27:77-84.

25. Peres W, Tuñion MJ, Hermann S, Marroni N, Gallego JG. The flavanoid quercetin ameliorates liver damage in rats with biliary obstruction. J Hepatol 2000;33:74250 .

26. Recknagel RO, Glende EA Jr., Dolak JA. Mechanisms of carbon tetrachloride toxicity. Pharmacol Ther 1989;43:139-54.

27. Rhoden EL, Pereira-Lima J, Rhoden CR, Mauri M, Pereira-Lima JC, Zettler CG, Barros, EG. The role of colchicine in prevention of hepatic cirrhosis induced by carbon tetrachloride. Hepatogastroenterology 1996;46:1111-5.

28. Rhoden EL, Mauri M, Petteffi L, Belló-Klein A, Rhoden CR. O estresse oxidativo na cirrose hepática induzida por tetracloreto de carbono em ratos. GED Gastroenterol Endosc Dig 1997;16:47-50.

29. Rodrigues L, Cerbon-Ambriz J, Munoz ML. Effects of colchicine and colchiceine in a biochemical model of liver injury and fibrosis. Arch Med Res 1998;29:10916.

30. Runyon BA, Sugano S, Kanel G, Mellencamp MA. A roodent model of cirrhosis, ascite, and bacterial peritonitis. Gastroenterology 1991;100:489-93.

31. Toledo C, Salmerón JM, Rimola A, Navasa M, Arroyo V, Llanch J, Ginés A, Ginés $\mathrm{P}$, Rodés J. Spontaneous bacterial peritonitis in cirrhosis: predictive factors of infection resolution and survival in patients treated with cefotaxime. Hepatology 1993;17:251-7.

32. Varela-Moreiras G, Alonso-Aperte E, Rubio M, Gassó M, Deulofeu R, Alvares L, Caballería J, Rodés J, Mato JM. Carbon tetrachloride-induced hepatic injury is associated with global DNA hypomethylation and homocysteinemia: effect of S-adenosylmethionine treatment. Hepatology 1995;22:1310-5. 